\title{
Effects of whole-grain rye porridge with added inulin and wheat gluten on appetite, gut fermentation and postprandial glucose metabolism: a randomised, cross-over, breakfast study
}

\author{
Isabella Lee ${ }^{1 *}$, Lin Shi ${ }^{1} \dagger$, Dominic-Luc Webb ${ }^{2}$, Per M. Hellström ${ }^{2}$, Ulf Risérus ${ }^{3}$ and Rikard Landberg ${ }^{1,4,5} \dagger$ \\ ${ }^{1}$ Department of Food Science, Swedish University of Agricultural Sciences, PO Box 7051, SE-750 07 Uppsala, Sweden \\ ${ }^{2}$ Department of Medical Sciences, Gastroenterology and Hepatology, Uppsala University, SE-751 85 Uppsala, Sweden \\ ${ }^{3}$ Department of Public Health and Caring Sciences, Clinical Nutrition and Metabolism, Uppsala University, SE-751 85 \\ Uppsala, Sweden \\ ${ }^{4}$ Unit of Nutritional Epidemiology, Institute of Environmental Medicine, Karolinska Institutet, PO Box 210, SE-171 77 \\ Stockbolm, Sweden \\ ${ }^{5}$ Department of Biology and Biological Engineering, Food and Nutrition Science, Chalmers University of Technology, \\ SE-41296 Gothenburg, Sweden \\ (Submitted 19 June 2016 - Final revision received 29 September 2016 - Accepted 7 November 2016 - First published online 10 January 2017)
}

\section{Abstract}

Whole-grain rye foods reduce appetite, insulin and sometimes glucose responses. Increased gut fermentation and plant protein may mediate the effect. The aims of the present study were to investigate whether the appetite-suppressing effects of whole-grain rye porridge could be enhanced by replacing part of the rye with fermented dietary fibre and plant protein, and to explore the role of gut fermentation on appetite and metabolic responses over $8 \mathrm{~h}$. We conducted a randomised, cross-over study using two rye porridges ( 40 and $55 \mathrm{~g}$ ), three $40-\mathrm{g}$ rye porridges with addition of inulin:gluten $(9: 3 ; 6: 6 ; 3: 9 \mathrm{~g})$ and a refined wheat bread control $(55 \mathrm{~g})$, served as part of complete breakfasts. A standardised lunch and an ad libitum dinner were served 4 and $8 \mathrm{~h}$ later, respectively. Appetite, breath hydrogen and methane, glucose, insulin and glucagon-like peptide-1 (GLP-1) responses were measured over $8 \mathrm{~h}$. Twenty-one healthy men and women, aged $23-60$ years, with BMI of $21-33 \mathrm{~kg} / \mathrm{m}^{2}$ participated in this study. Before lunch, the $55-\mathrm{g}$ rye porridges lowered hunger by $20 \%$ and desire to eat by $22 \%$ and increased fullness by $29 \%$ compared with wheat bread $(P<0.05)$. Breath hydrogen increased proportionally to dietary fibre content $(P<0.05)$. Plasma glucose after lunch was $6 \%$ lower after the 55 -g rye porridges compared with wheat bread $(P<0.05)$ and correlated to breath hydrogen $(P<0 \cdot 001)$. No differences were observed in ad libitum food intake, insulin or GLP-1. We conclude that no further increase in satiety was observed when replacing part of the rye with inulin and gluten compared with plain rye porridges.

Key words: Rye: Inulin: Satiety: Metabolic responses: Gluten

Development and optimisation of food products with appetitesuppressing properties represent a strategy to combat the increasing global prevalence of overweight and obesity ${ }^{(1,2)}$. Food products affect appetite and metabolism differently depending on their content of energy and macronutrients, as well as their physiochemical attributes. Previous studies have indicated that isoenergetic intakes of macronutrients do not suppress appetite to the same magnitude; dietary fibre-rich carbohydrates and proteins have been shown to be more satiating than fats ${ }^{(1)}$.

Whole-grain rye food products that are naturally rich in dietary fibre, such as porridge, soft bread and crisp bread, have consistently shown appetite-suppressing effects in human studies ${ }^{(3-14)}$.
Moreover, whole-grain rye foods promote tighter regulation of postprandial glucose $\mathrm{e}^{(4,6,8,10,11,14,15)}$ and insulin concentrations ${ }^{(3,4,6,8,10,11,14,15)}$ and influence gut hormones associated with appetite, such as glucagon-like peptide 1 (GLP-1), which potentiates glucose-induced insulin secretion and slows gastric emptying ${ }^{(4,6,16,17)}$, leading to increased satiety ${ }^{(2,18)}$. Appetite, metabolic and hormonal responses are believed to be affected by SCFA produced during gut fermentation of dietary fibre $e^{(4,19-21)}$. However, the relationship between satiety and gut fermentation is typically confounded by other aspects of dietary fibre such as volume and viscosity, and thus the role of fermentation per se is difficult to evaluate ${ }^{(20)}$.

Abbreviations: GLP-1, glucagon-like peptide-1; RP40, 40-g rye porridge; RP55, 55-g rye porridge; RPHG, 40-g rye porridge with inulin:wheat gluten 3:9 g; RPHI, 40-g rye porridge with inulin:wheat gluten 9:3 g; RPIG, 40-g rye porridge with inulin:wheat gluten 6:6 g; WB, refined wheat bread.

* Corresponding author: I. Lee, fax +468717 0669, email isabella.t.lee@gmail.com

$\dagger$ Present address: Department of Biology and Biological Engineering, Chalmers University of Technology, Göteborg, Sweden. 
Among macronutrients, protein is considered to be the most satiating $^{(1,22,23)}$, although evidence is scarce on the effects of proteins from different sources, especially plant proteins, and the underlying physiochemical properties are not fully understood $^{(22)}$. The effects of proteins on appetite are possibly mediated by diet-induced thermogenesis, secretion of gut hormones, for example, GLP-1, and stimulated secretion of insulin by absorbed amino acids ${ }^{(1,22)}$

We hypothesised that extensive fermentation in the first part of the large intestine caused by inulin would stimulate GLP-1 secretion and promote satiety $4-8 \mathrm{~h}$ after ingestion. We further hypothesised that rye porridge with high protein content would lead to higher satiety compared with products with lower protein content. The primary aim of this study was therefore to investigate whether appetite-suppressing effects of whole-grain rye porridge could be enhanced by replacing part of the rye with rapidly fermented dietary fibre (inulin) and plant protein (wheat gluten). The secondary aim was to investigate the role of gut fermentation on appetite and postprandial glucose and hormonal responses up to $8 \mathrm{~h}$ after breakfast.

\section{Methods}

\section{Subjects}

Men and women aged 18-60 years were recruited from Uppsala, Sweden, through local advertisements. Recruitment started in March 2013, and the study was carried out until the end of August 2013 when all the enrolled subjects had completed the intervention. Screening, including measurements of anthropometrics and biomarkers in fasting blood samples, was conducted to ensure that subjects were overtly healthy. Subjects completed questionnaires regarding health, medication use, allergies, diets, tobacco use, physical activity and eating behaviour (Three-Factor Eating Questionnaire (TFEQ) in a revised version R18) ${ }^{(24,25)}$. Exclusion criteria were as follows: presence of diabetes, hyperglycaemia, hyperinsulinaemia, thyroid disease and metabolic issues; pregnancy, lactation or planned pregnancy; eating disorders; dieting or weight loss $>10 \% 3$ months before screening; recent or concurrent dietary study participation; nonhabitual breakfast eaters; intolerances or allergies to study foods; and heavy smokers. Only post-menopausal women or women using hormonal contraceptives were included in the study, to avoid the influence of cyclic fluctuations in hormones on eating behaviour ${ }^{(26)}$. Before enrolment, subjects tried the test product with the highest amount of dietary fibre to prevent inclusion of subjects sensitive to foods rich in dietary fibre, with an aversion to the test product or with problems eating breakfast.

\section{Ethics approval}

This study was conducted according to the guidelines laid down in the Declaration of Helsinki, and all procedures involving human subjects were approved by the Regional Ethical Review Board, Uppsala, Sweden. Written informed consent was obtained from all subjects. The study was registered in the public trials registry ClinicalTrials.gov, ID: NCT01965210 (https://clinicaltrials.gov/ct2/show/NCT01965210).

\section{Design}

The present study was designed as a randomised, extended postprandial, single-blind, cross-over study with six breakfast meals served in random order with a wash-out period of $\geq 5 \mathrm{~d}$ in between. Subjects were not informed about the content of the breakfast meals, and were randomly assigned to a randomly generated breakfast meal sequence as they were enrolled in the study. On the morning of the study visits, subjects arrived fasted (for $12 \mathrm{~h}$ ) to the clinic at Uppsala University Hospital, Sweden. Subjects were instructed to avoid strenuous physical activity and to exclude alcohol and dietary fibre-rich foods according to dietary guidance during the whole day before each study visit. Upon arrival, an intravenous catheter was inserted into the antecubital vein for repeated blood sampling. Capillary samples may be superior to venous antecubital venous samples for determining blood glucose concentrations and the glycaemic index of food. However, because of extensive sampling and other measurements conducted, we decided to only collect antecubital venous samples. Antecubital vein blood sampling has been widely used in several studies for measuring postprandial glucose concentrations, in designs similar to ours ${ }^{(27-29)}$. Baseline measurements of appetite and breath hydrogen and methane were made (at $-30 \mathrm{~min}$ ), and blood samples were drawn (at $-15 \mathrm{~min}$ ). The prepared breakfast meal was served immediately after the second appetite rating (at $0 \mathrm{~min}$ ). Subjects were seated together while eating and allowed to make conversation, but not regarding anything related to the study or food, and were instructed to finish the breakfast meal within $15 \mathrm{~min}$. Subjects remained at the clinic and were limited to sedentary activities, for example, using a laptop or reading, and were allowed to visit the outdoor terrace area when the blood sampling schedule permitted in the late afternoon. Commercially available ready meals were served for lunch and dinner (at 240 and $480 \mathrm{~min}$, respectively), as $4 \mathrm{~h}$ between meals was considered a realistic and appropriate time interval ${ }^{(30)}$. Lunch was a pre-portioned standardised meal consisting of sausage Stroganoff with rice (Carolines Kök), with an average portion weight of 405 (sD 23$) \mathrm{g}(3875 \mathrm{~kJ}$, protein $4 \mathrm{~g}$, fat $7.1 \mathrm{~g}$, available carbohydrates $15.5 \mathrm{~g}$, dietary fibre $0.1 \mathrm{~g}$ ) and one standard glass of tap water, served in the hospital restaurant. Dinner was an ad libitum meal of pasta Bolognese (Findus) and one standard glass of tap water, served in the breakfast room. Energy intake at dinner was calculated on the basis of the weight difference between food supplied and food remaining. Subjects were instructed to finish both meals within $30 \mathrm{~min}$, and to eat until comfortably full at the ad libitum dinner meal. The nutrient composition of the lunch and dinner meals was based on the manufacturers' data (online Supplementary Table S1). Subjects were not allowed to eat or drink anything that was not included in the study diet.

\section{Test meals}

The breakfast meals consisted of six isoenergetic products served as part of a complete breakfast: five whole-grain rye porridge meals and one refined wheat bread (WB) meal as reference. WB has been the common reference product in 
earlier appetite studies including rye, and was therefore chosen in order to facilitate comparisons ${ }^{(13)}$. The rye porridges were prepared from commercially available whole-grain rye flakes made from cut, steamed and rolled rye kernels (Lantmännen Cerealia AB). Among the five rye porridges tested, two contained $40 \mathrm{~g}$ of rye flakes (RP40) and $55 \mathrm{~g}$ of rye flakes (RP55), respectively, whereas three contained $40 \mathrm{~g}$ of rye flakes with $15 \mathrm{~g}$ of a combination of inulin (Orafti ${ }^{\circledR} \mathrm{GR}$ inulin, purity $90 \%$; Beneo $\mathrm{GmbH}$ ) and wheat gluten (Vital Wheat Gluten, purity $77 \%$; Arrowhead Mills Inc.). Recipes were re-calculated to compensate for impurities to provide inulin and wheat gluten in a ratio of 9:3 g (RPHI), 6:6 g (RPIG) or 3:9 g (RPHG). Inulin with an average degree of polymerisation of 10 was chosen, as it undergoes rapid gut fermentation and does not increase viscosity or bulking to the same extent as many other fermentable dietary fibres from, for example, cereals ${ }^{(31)}$. Sensory evaluations of isolated plant proteins from rice, potato, pea and wheat were performed. Wheat gluten was chosen as it had the most appealing flavour when added to porridge. Porridge material was stored and prepared in unlabelled opaque paper cups with lids, which concealed the content. Dry material was manually stirred thoroughly, boiling water was added, and porridge was manually stirred thoroughly and allowed to rest for $2 \mathrm{~min}$ while margarine (Unilever Sverige AB) was added. Porridge was again manually stirred thoroughly and allowed to rest for $2 \mathrm{~min}$, and $25 \mathrm{~g}$ raspberry jam (Orkla Foods Sverige AB) was added on top. Porridge was served immediately after preparation. Different amounts of water were added to ensure similar viscosity of the porridges: $150 \mathrm{ml}$ of water was added to the four porridges samples containing $40 \mathrm{~g}$ of rye flakes, whereas $200 \mathrm{ml}$ of water was added to the porridge sample containing $55 \mathrm{~g}$ of rye flakes. The WB reference was made from 55-g commercially available refined soft WB (Pågen $\mathrm{AB}$ ) served with margarine (Unilever Sverige $\mathrm{AB}$ ) and $25 \mathrm{~g}$ raspberry jam (Orkla Foods Sverige AB). Breakfast meals also included $100 \mathrm{ml}$ of milk (Arla Foods $\mathrm{AB}$ ) and $150 \mathrm{ml}$ of coffee or tea, whereas the amount of margarine was varied to make the breakfast meals isoenergetic. The ingredients of the breakfast meals are presented in Table 1.

\section{Chemical analysis}

Prepared porridges and bread were freeze-dried and homogenised in an ultra-centrifugal mill (ZM-1; Retsch $\mathrm{GmbH}$ ). Crude fat content was determined by method $\mathrm{B}$ in Commission Directive 98/64/EC ${ }^{(32)}$, and crude protein content was determined by the Kjeldahl method with a conversion factor of $6 \cdot 25^{(33)}$ at Kungsängen Laboratory, Uppsala, Sweden. Dietary fibre (extractable and unextractable) and total glucose were determined by the Uppsala method ${ }^{(34)}$. Resistant starch, fructan and $\beta$-glucan contents were determined using assay kits $\mathrm{K}_{-R S T A R}{ }^{(35)}, \mathrm{K}_{-} \mathrm{FRUC}^{(36)}$ and $\mathrm{K}-\mathrm{BGLU}^{(37)}$, respectively (Megazyme). Total content of extractable dietary fibre was calculated as the sum of extractable dietary fibre and fructan. Cellulose content was calculated by subtracting resistant starch and $\beta$-glucan content from total glucose. Arabinogalactan content was calculated as the sum of galactose and arabinose content that is part of arabinogalactan ${ }^{(38)}$. Arabinoxylan content was calculated as the sum of xylose and galactose, after correcting
Table 1. Ingredients, nutrient composition (g/portion) and energy (\%) in the different breakfast meals tested in the study

\begin{tabular}{|c|c|c|c|c|c|c|}
\hline Ingredients & $\mathrm{RPHI}$ & RPIG & RPHG & RP55 & RP40 & WB \\
\hline Rye flakes & $40 \cdot 0$ & $40 \cdot 0$ & $40 \cdot 0$ & $55 \cdot 0$ & $40 \cdot 0$ & \\
\hline Inulin* & $10 \cdot 0$ & $6 \cdot 7$ & $3 \cdot 3$ & & & \\
\hline Wheat gluten $†$ & 3.9 & $7 \cdot 8$ & 11.7 & & & \\
\hline Wheat bread & & & & & & $55 \cdot 0$ \\
\hline Margarine $39 \%$ & $7 \cdot 0$ & $5 \cdot 0$ & 3.0 & 4.0 & $17 \cdot 0$ & $12 \cdot 0$ \\
\hline Milk $1.5 \%$ & $100 \cdot 0$ & $100 \cdot 0$ & $100 \cdot 0$ & $100 \cdot 0$ & $100 \cdot 0$ & $100 \cdot 0$ \\
\hline Raspberry jam & $25 \cdot 0$ & $25 \cdot 0$ & $25 \cdot 0$ & $25 \cdot 0$ & $25 \cdot 0$ & $25 \cdot 0$ \\
\hline Coffee or tea & $150 \cdot 0$ & $150 \cdot 0$ & $150 \cdot 0$ & $150 \cdot 0$ & $150 \cdot 0$ & $150 \cdot 0$ \\
\hline Water & $150 \cdot 0$ & $150 \cdot 0$ & $150 \cdot 0$ & $200 \cdot 0$ & $150 \cdot 0$ & \\
\hline Total weight & $485 \cdot 9$ & 484.5 & 483.0 & $534 \cdot 0$ & $482 \cdot 0$ & $342 \cdot 0$ \\
\hline \multicolumn{7}{|l|}{ Nutrient composition } \\
\hline Energy (kJ) & $1186 \cdot 7$ & 1185.5 & $1191 \cdot 8$ & $1205 \cdot 1$ & $1191 \cdot 3$ & $1157 \cdot 9$ \\
\hline Energy (kcal) & $283 \cdot 6$ & $283 \cdot 3$ & $284 \cdot 8$ & $288 \cdot 0$ & $284 \cdot 7$ & $276 \cdot 7$ \\
\hline Fat & $5 \cdot 0$ & 4.0 & 4.0 & 4.0 & 9.0 & 8.0 \\
\hline \multicolumn{7}{|l|}{ Protein } \\
\hline Total & $10 \cdot 0$ & $13 \cdot 1$ & $16 \cdot 2$ & $8 \cdot 2$ & $7 \cdot 0$ & $10 \cdot 4$ \\
\hline EAA & $2 \cdot 0$ & $2 \cdot 7$ & 3.5 & 1.4 & 1.0 & $2 \cdot 0$ \\
\hline BCAA‡ & 1.0 & 1.4 & $1 \cdot 8$ & 0.7 & 0.5 & 1.0 \\
\hline Carbohydrates & $42 \cdot 3$ & $41 \cdot 8$ & 41.5 & $50 \cdot 3$ & $41 \cdot 2$ & $39 \cdot 0$ \\
\hline \multicolumn{7}{|l|}{ Dietary fibre§ } \\
\hline Total & $15 \cdot 5$ & $12 \cdot 6$ & $10 \cdot 4$ & 9.7 & $7 \cdot 1$ & $3 \cdot 4$ \\
\hline Extractable‡\|l & 11.0 & $8 \cdot 1$ & $5 \cdot 8$ & 3.6 & 2.6 & 0.9 \\
\hline Unextractablef & 4.5 & 4.5 & 4.6 & $6 \cdot 1$ & 4.5 & 2.5 \\
\hline $\begin{array}{l}\text { Resistant starch and } \\
\text { cellulose } \neq\end{array}$ & 0.4 & 0.5 & 0.6 & 0.6 & 0.4 & 1.0 \\
\hline Fructan $\ddagger$ & $9 \cdot 8$ & 6.9 & 4.5 & $2 \cdot 0$ & 1.5 & 0.2 \\
\hline$\beta$-Glucan $\ddagger$ & 0.8 & 0.8 & 0.8 & 1.0 & 0.8 & 0.1 \\
\hline Klason lignin $\ddagger$ & 0.4 & 0.4 & 0.4 & 0.6 & 0.4 & 0.3 \\
\hline \multicolumn{7}{|l|}{ Arabinoxylan $\ddagger$} \\
\hline Total & $2 \cdot 1$ & $2 \cdot 1$ & $2 \cdot 1$ & $2 \cdot 8$ & 2.0 & 0 \\
\hline Extractable & 0.6 & 0.6 & 0.7 & 0.8 & 0.6 & 0.4 \\
\hline Unextractable & 1.4 & 1.5 & 1.5 & $2 \cdot 0$ & 1.4 & 0.3 \\
\hline Arabinogalactan $\ddagger \mathbb{~}$ & 1.4 & 1.4 & 1.4 & $1 \cdot 8$ & $1 \cdot 3$ & 0.5 \\
\hline Water & $262 \cdot 7$ & 261.5 & $260 \cdot 5$ & $311 \cdot 2$ & $267 \cdot 5$ & $130 \cdot 0$ \\
\hline \multicolumn{7}{|l|}{ Energy (\%) } \\
\hline Fat & 16 & 14 & 12 & 12 & 28 & 26 \\
\hline Protein & 14 & 18 & 23 & 11 & 10 & 15 \\
\hline Carbohydrates & 60 & 59 & 58 & 70 & 58 & 56 \\
\hline Dietary fibre & 11 & 9 & 7 & 7 & 5 & 2 \\
\hline
\end{tabular}

RPHI, porridge: $40-\mathrm{g}$ rye flakes inulin:wheat gluten 9:3 g; RPIG, porridge: 40 -g rye flakes inulin:wheat gluten 6:6 g; RPHG, porridge: 40-g rye flakes inulin:wheat gluten 3:9 g; RP55, porridge: 55-g rye flakes; RP40, porridge: 40-g rye flakes; WB, 55-g refined wheat bread; EAA, essential amino acids; BCAA, branched-chain amino acids.

* Inulin purity $90 \%$

$\dagger$ Wheat gluten purity $77 \%$.

¥ Not including content in additional food items.

$\S$ Calculated as the sum of fructan and total dietary fibre as analysed by the Uppsala method.

\| Calculated as the sum of fructan and total extractable dietary fibre as analysed by the Uppsala method.

If Calculated from the sum of arabinose, xylose and galactose assuming an arabinose:extractable galactose ratio of 0.69 in arabinogalactan.

for arabinose assuming an arabinose:galactose ratio of 0.69 in extractable arabinogalactan ${ }^{(38)}$. Available starch/carbohydrate content was calculated by the difference, that is, by subtracting water, protein, fat, ash and total dietary fibre from total dry weight. The composition of total amino acids was determined by the EN ISO 13903:2005 and EN ISO 13904:2005 methods as described by Johansson et al. ${ }^{(39)}$ at a certified commercial testing laboratory (Eurofins $\mathrm{AB}$ ). The nutrient composition of additional breakfast foods was based on manufacturers' data. Energy was calculated using standard food energy conversion factors: protein and available carbohydrates $17 \mathrm{~kJ} / \mathrm{g}$, fat $37 \mathrm{~kJ} / \mathrm{g}$ 
and dietary fibre $8 \mathrm{~kJ} / \mathrm{g}$. The nutrient composition and energy content of breakfast meals are presented in Table 1 , whereas the amino acid composition of products is presented in the online Supplementary Table S2.

\section{Appetite ratings}

Subjective feelings of appetite (hunger, fullness and desire to eat) were assessed by asking the following three questions on a unipolar visual analogue scale (VAS): (1) how hungry do you feel right now? (not at all hungry/extremely hungry), (2) how full do you feel right now? (not at all full/extremely full), (3) how strong is your desire to eat right now? (not at all strong/ extremely strong). The questions were presented in sequence on a hand-held Palm computer (Palm z22; Palm Inc.) using a specially designed programme that is comparable with conventional paper $100-\mathrm{mm} \mathrm{VAS}^{(40)}$. Subjects indicated their answers by making a vertical line along the scale shown on the touch screen, which was translated to a value between 0 and 100. An alarm signalled each appetite rating, and it was not possible to refer to previous ratings. Subjects indicated appetite ratings on paper 100-mm VAS when the hand-held computer was not functioning properly. Appetite rating VAS were completed eighteen times during the day starting before breakfast at -30 and $0 \mathrm{~min}$ and continued after breakfast at $+30,+60,+90$, $+120,+150,+180,+210,+240,+270,+300,+330,+360,+390$, $+420,+450$ and $+480 \mathrm{~min}$.

\section{Breath hydrogen and methane measurements}

Excretion of hydrogen and methane via breath was measured as indicators of gut fermentation ${ }^{(41)}$. After calibration with a reference gas mixture, exhaled breath was collected in a special collection system (AlveoSampler; QuinTron Instrument Company Inc.), and a minimum of $20 \mathrm{ml}$ of each breath sample was analysed using a breath hydrogen and methane analyser (QuinTron BreathTracker DP; QuinTron Instrument Company Inc.). Measurements were taken directly after completion of appetite ratings and were made ten times during the day starting before breakfast at $-30 \mathrm{~min}$ and continued after breakfast at $+30,+90,+150,+210,+270,+330,+390,+450$ and $+480 \mathrm{~min}$.

\section{Blood collection and measurements}

Venous blood samples were collected by trained nurses into ice-cold vacutainer ${ }^{\circledR}$ tubes: two plasma tubes prepared with potassium EDTA and one plasma tube with lithium heparin (Sarstedt AG \& Co.). Immediately after sample collection, a protease inhibitor cocktail $(160 \mu \mathrm{l})$ was added to the EDTA tubes to prevent degradation of GLP-1 ${ }^{(42)}$. The inhibitor cocktail was prepared daily by dissolving 1 SIGMAFAST ${ }^{\text {TM }}$ Protease Inhibitor tablet (catalogue no. S8820; Sigma-Aldrich Co.) in $2.2 \mathrm{ml} \mathrm{H}_{2} \mathrm{O}$ containing $5.5 \mu \mathrm{l} 10 \mathrm{~mm}$-dipeptidyl peptidase-IV inhibitor KR-62436 (catalogue no. K4264; Sigma-Aldrich) in dimethyl sulfoxide (Sigma-Aldrich). The mixture was vortexed until transparent and kept on ice. Blood samples were drawn twelve times during the day starting before breakfast at $-15 \mathrm{~min}$ and continuing after breakfast at $+15,+35,+65,+95,+125,+185$,
$+230,+275,+305,+365$ and $+470 \mathrm{~min}$. On each occasion, $10 \mathrm{ml}$ of blood was collected (in total $120 \mathrm{ml}$ ) and kept on ice. Plasma was separated from erythrocytes and buffy coat by centrifugation at $4^{\circ} \mathrm{C}$ for $10 \mathrm{~min}$ at $2000 \mathrm{~g}$, and aliquoted into $2 \cdot 0-\mathrm{ml}$ screwcap microtubes (Sarstedt AG \& Co.). Samples were initially stored at $-20^{\circ} \mathrm{C}$ for a maximum of 1 week and then stored at $-80^{\circ} \mathrm{C}$ until analysed. EDTA plasma samples were analysed for glucose (Architect c16000; Abbott Laboratories) and insulin (Cobas $^{\mathrm{TM}}$ C8000 e602 analyser; Roche Diagnostics GmbH) at the certified laboratory of the Department of Clinical Chemistry at Uppsala University Hospital. The CV were $<4$ and $<3 \%$, respectively. Total GLP-1 (7-36 and 9-36) was analysed in EDTA plasma samples using the Multi Species GLP-1 Total ELISA kit ${ }^{(43)}$ (EZGLP1T-36K; EMD Millipore) in order to investigate the potential impact of gut fermentation on GLP-1 after intake of RPHI, RP55 and WB. Kits with the same lot number were used in the analysis and the sensitivity limit of the kit, as provided by the manufacturer, was $1.5 \mathrm{pmol} / 1$ total GLP-1 (50 $\mu \mathrm{l}$ sample size). Samples from seven subjects were, however, excluded from the GLP-1 analysis because of lack of inhibitor cocktail added during sampling. The approximate assay range was $4 \cdot 12-1000 \mathrm{pmol} / \mathrm{l}$. The intra- and inter-assay $\mathrm{CV}$ were $<10$ and $<15 \%$, respectively.

\section{Statistical analysis}

We used two ANCOVA models to evaluate differences between breakfast meals (referred to as 'treatments') in the following response variables: hunger, fullness, desire to eat, hydrogen, methane, glucose, insulin, GLP-1 and ad libitum food intake, using PROC MIXED in SAS (version 9.3; SAS Institute Inc.). In the first model, the effect of treatment (RPHI, RPIG, RPHG, RP55, RP40, WB), time, sex, occasion, treatment $\times$ time, treatment $\times$ sex and treatment $\times$ occasion were included as independent variables. Subject was entered as a random effect variable, and the baseline value was entered as a covariate. Interaction terms were removed from the final models if they were not statistically significant. Differences in response variables were tested for different time intervals for hunger, fullness and desire to eat: whole day (0-480 min), after breakfast (0-120 min), before lunch (0-240 min) and after lunch (270-480 min); hydrogen and methane: whole day ( -30 to $480 \mathrm{~min}$ ); and glucose, insulin and GLP-1: whole day ( -15 to $470 \mathrm{~min}$ ), after breakfast ( -15 to $125 \mathrm{~min}$ ), before lunch ( -15 to $230 \mathrm{~min}$ ) and after lunch ( 275 to $470 \mathrm{~min}$ ).

In the second model, AUC over time was calculated for each subject and response variables by the trapezoidal rule, using the same independent variables (except for time and treatment $x$ time) and covariates as in the first model. Differences in response variables were tested for different AUC time intervals for hunger, fullness, desire to eat: whole day $\left(\mathrm{AUC}_{0-480 \mathrm{~min}}\right)$, before lunch $\left(\mathrm{AUC}_{0-240 \mathrm{~min}}\right)$ and after lunch $\left(\mathrm{AUC}_{270-480 \mathrm{~min}}\right)$; hydrogen and methane: whole day $\left(\mathrm{AUC}_{0-480 \mathrm{~min}}\right)$; and glucose, insulin and GLP-1: whole day $\left(\mathrm{AUC}_{15-470 \mathrm{~min}}\right)$, after breakfast $\left(\mathrm{AUC}_{15-125 \mathrm{~min}}\right)$, before lunch $\left(\mathrm{AUC}_{15-230 \mathrm{~min}}\right)$ and after lunch $\left(\mathrm{AUC}_{275-470 \mathrm{~min}}\right)$. The within-subject correlation between hydrogen, appetite and blood glucose after lunch was investigated by regression analysis according to the method of Bland 
\& Altman ${ }^{(44)}$. Spearman's correlation coefficient was used to study the relationship of breath hydrogen and dietary fibre in diets. Unless otherwise indicated, data presented are modeladjusted least-squares means with standard error of the mean, and missing values were imputed before analysis. All probability $(P)$ values presented were Bonferroni corrected to take multiple comparisons into account, and the results were considered statistically significant at $P<0 \cdot 05$. A total of eighteen subjects is sufficient to detect a $10 \%$ difference in appetite ratings in different conditions, as well as glucose response, between two treatments at a power of $80 \%$ and a level of significance of $P<0.05$ using a paired design ${ }^{(45,46)}$.

\section{Results}

\section{Subject characteristics}

A total of forty-two subjects were initially screened, and twentyfive were enrolled into the study. Among them, twenty-one healthy subjects (eleven men and ten women) with a mean age of 38.6 ( $\mathrm{SD} 11.8$ ) years, range 23-60 years, and BMI of 24.9 (sD 3.3$) \mathrm{kg} / \mathrm{m}^{2}$, range $21-33 \mathrm{~kg} / \mathrm{m}^{2}$, completed the study (Table 2); four subjects discontinued the study due to lack

Table 2. Characteristics of the study subjects

(Mean values and standard deviations)

\begin{tabular}{lcccccccc}
\hline & \multicolumn{2}{c}{ All $(n$ 21 $)$} & & \multicolumn{2}{c}{ Males $(n$ 11) } & & \multicolumn{2}{c}{ Females $(n ~ 10)$} \\
\cline { 2 - 3 } Characteristics & Mean & SD & & Mean & SD & & Mean & SD \\
\hline Age (years) & 38.6 & 11.8 & & 35.5 & 10.3 & & 42.0 & 13.0 \\
Height $(\mathrm{m})$ & 1.74 & 0.11 & & 1.81 & 0.10 & & 1.67 & 0.07 \\
Weight $(\mathrm{kg})$ & 75.7 & 12.9 & & 78.3 & 13.5 & & 72.9 & 12.3 \\
BMl $\left(\mathrm{kg} / \mathrm{m}^{2}\right)$ & 24.9 & 3.3 & & 23.9 & 3.0 & & 26.0 & 3.5 \\
\hline
\end{tabular}

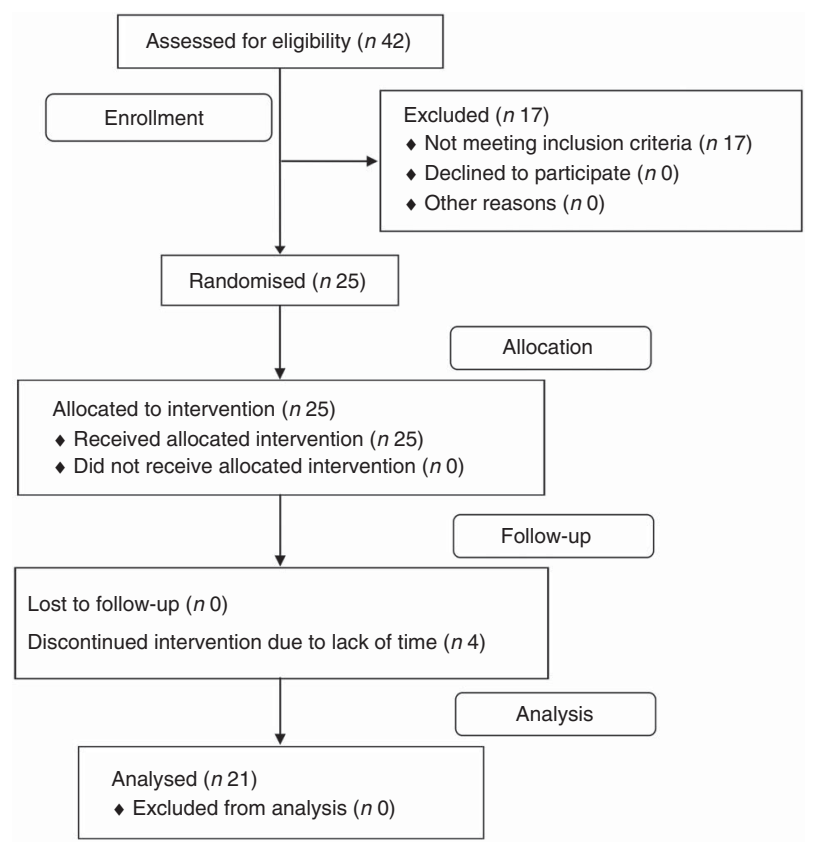

Fig. 1. Flow chart of the study process. of time. A study process flow chart is presented in Fig. 1. All women used hormonal contraceptives, except two who were post-menopausal. One subject was prescribed antibiotics for medical reasons during one of the test occasions and was included in the data analysis, as excluding the subject from the analysis did not change the results. One subject reported smoking one to two cigarettes per day, but abstained during visit days. Three subjects were prescribed selective serotonin re-uptake inhibitors. All except one scored within the normal range of the TFEQ and were included in the data analysis. The subject scoring above the cut-off on emotional eating was included in the data analysis, as excluding the subject from the analysis did not change the results. The analysis of subjective appetite, ad libitum food intake, glucose and insulin included twenty-one subjects, the analysis of breath hydrogen and methane included seventeen subjects, and the analysis of total GLP-1 included fourteen subjects.

\section{Appetite ratings and food intake}

In the fasted state before breakfast, no differences between hunger, fullness and desire to eat were observed between breakfast meals. Subjects reported lower hunger during the whole day (0-480 min) after consumption of the 55-g rye porridge meals (except RPHG) compared with WB and for RP55 compared with RP40 $(P<0 \cdot 05)$. Similarly, for $\mathrm{AUC}_{0-480 \mathrm{~min}}$, intake of the 55-g rye porridge meals (except RPHG) resulted in, on average, $16 \%(P<0.05)$ lower hunger compared with WB. Hunger was $20 \%(P<0 \cdot 05)$ lower for $\mathrm{AUC}_{0-240 \text { min }}$ after consumption of RP55 and RPHI compared with WB (Fig. 2).

Subjects reported higher fullness before lunch (0-240 min) and also during the whole day (0-480 min) after consumption of RPHI compared with WB $(P<0 \cdot 05)$. Fullness was on average $18 \%(P<0.05)$ higher for $\mathrm{AUC}_{0-480 \mathrm{~min}}$ and $29 \%(P<0.05)$ higher for $\mathrm{AUC}_{0-240 \mathrm{~min}}$ after intake of the $55-\mathrm{g}$ rye porridge meals (except RPHG) compared with WB. Likewise, for $\mathrm{AUC}_{0-120 \mathrm{~min}}$, consumption of the 55 -g rye porridge meals (except RPHI) resulted in, on average, 25\% $(P<0.05)$ higher fullness compared with WB (Fig. 3).

Subjects reported lower desire to eat before lunch (0-240 min) after consumption of RPHI compared with RP40 $(P<0.05)$. Similarly, for $\mathrm{AUC}_{0-240 \text { min }}$, intake of RPHI resulted in $25 \%(P<0.01)$ lower desire to eat compared with RP40 and $22 \%(P<0.05)$ lower desire to eat compared with WB (Fig. 4).

Overall, subjective ratings of hunger, fullness and desire to eat did not differ between men and women, and no differences in food intake at the ad libitum dinner $8 \mathrm{~h}$ after breakfast were observed between breakfast meals (online Supplementary Table S3).

\section{Breath hydrogen and methane concentrations}

The concentration of hydrogen in breath was higher during the whole day ( -30 to $480 \mathrm{~min}$ ) after consumption of the $55-\mathrm{g}$ rye porridge meals compared with WB $(P<0.01)$ and for RPHI and RPIG compared with RP40 $(P<0 \cdot 001)$. Similarly, for $\mathrm{AUC}_{0-480 \mathrm{~min}}$, intake of the 55-g rye porridge meals resulted in, on average, 3-fold $(P<0.0001)$ higher breath hydrogen concentrations compared with WB. Intake of RPHI and RPIG 
(A)

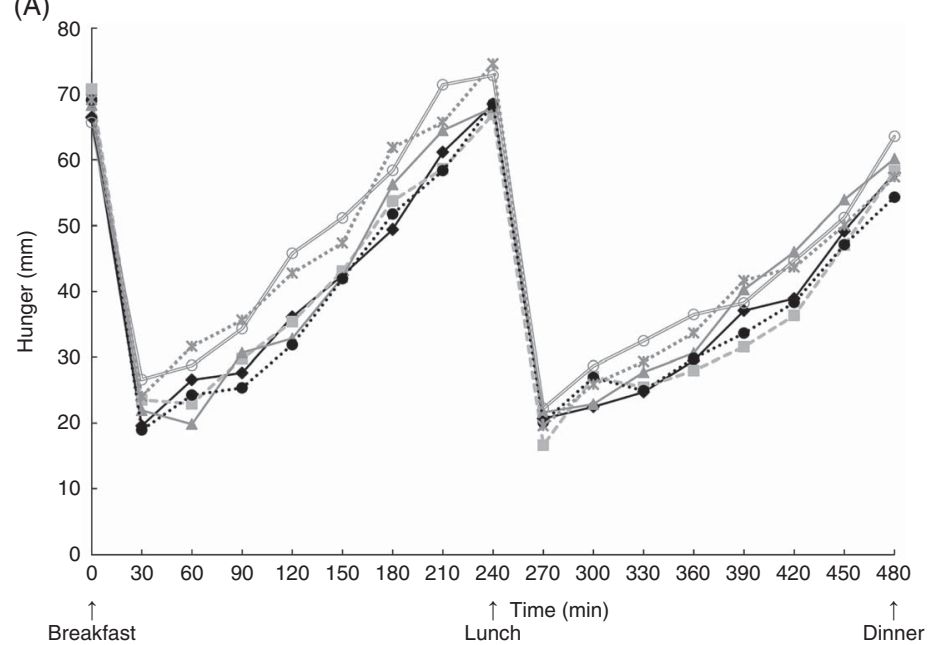

(B)

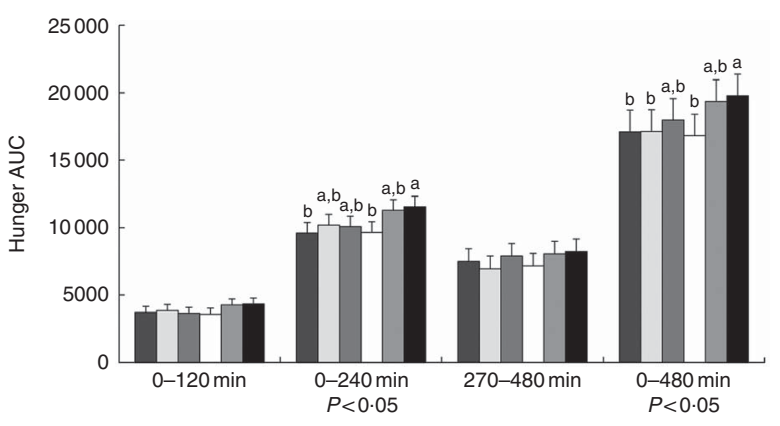

Fig. 2. (A) Mean subjective ratings of hunger $(n 21)$ during the whole day (0-480 min) after intake of six isoenergetic breakfast meals. Subjects reported less hunger during the whole day after intake of RPHI, RPIG and RP55 compared with WB, and RP55 compared with RP40 ( $P<0.05)$. (B) AUC for subjective hunger ( $n 21)$ before breakfast (0-120 min), before lunch (0-240 min), after lunch (270-480 min) and during the whole day (0-480 min) after intake of six isoenergetic breakfast meals. ${ }^{\mathrm{a}, \mathrm{b}}$ Mean values with unlike letters were significantly different $(P<0.05)$. Analysed by ANCOVA. RP40, porridge: $40-\mathrm{g}$ rye flakes; RP55, porridge: $55-\mathrm{g}$ rye flakes; RPHG, porridge: 40-g rye flakes inulin:wheat gluten 3:9 g; RPHI, porridge: 40-g rye flakes inulin:wheat gluten 9:3 g; RPIG, porridge: 40-g rye flakes inulin:wheat gluten

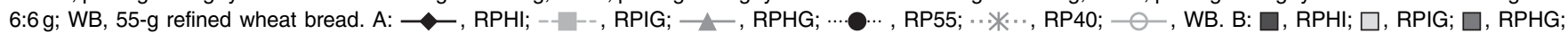
$\square$, RP55; $\square$, RP40; $\square$, WB.
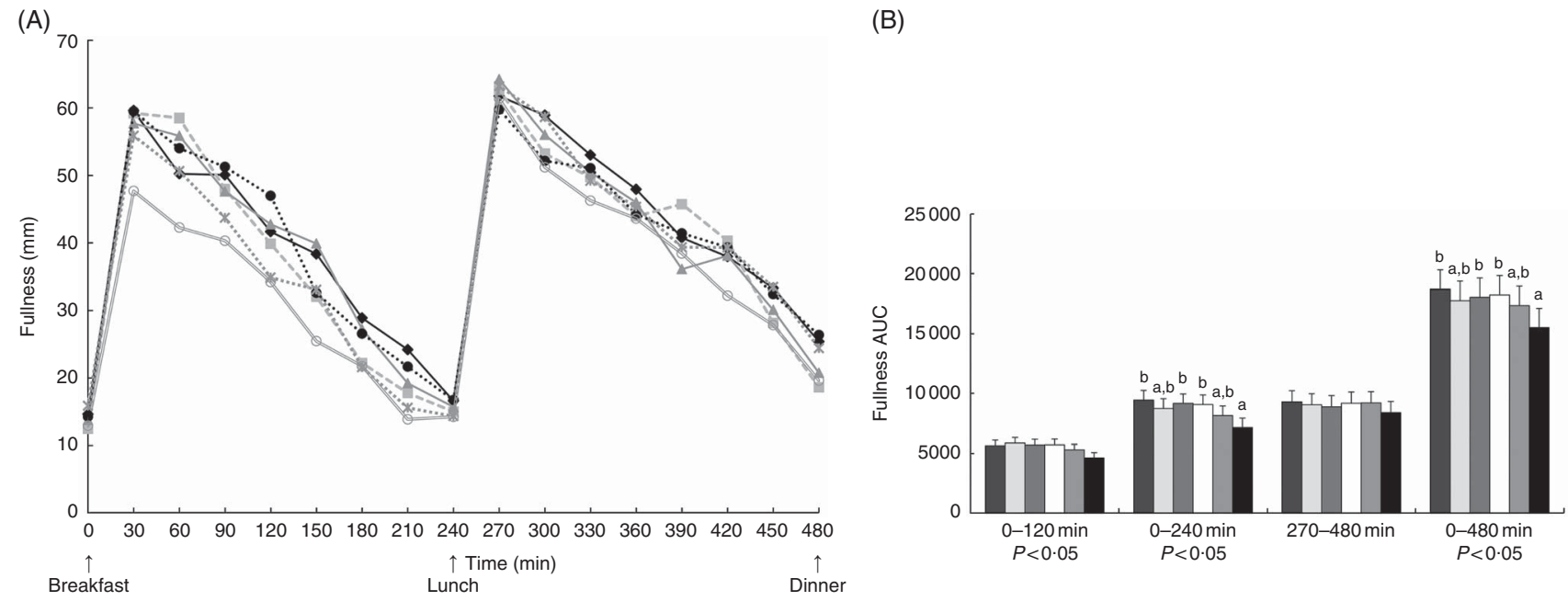

Fig. 3. (A) Mean subjective ratings of fullness $(n 21)$ during the whole day $(0-480 \mathrm{~min}$ ) after intake of six isoenergetic breakfast meals. Subjects reported higher fullness during the whole day and before lunch from intake of RPHI compared with WB $(P<0.05)$. (B) AUC for subjective fullness $(n 21)$ after breakfast $(0-120$ min), before lunch $(0-240 \mathrm{~min})$, after lunch $(270-480 \mathrm{~min})$ and during the whole day $(0-480 \mathrm{~min})$ after intake of six isoenergetic breakfast meals. ${ }^{\mathrm{a}, \mathrm{b}}$ Mean values with unlike letters were significantly different $(P<0.05)$. Analysed by ANCOVA. RP40, porridge: 40-g rye flakes; RP55, porridge: $55-\mathrm{g}$ rye flakes; RPHG, porridge: $40-\mathrm{g}$ rye flakes inulin:wheat gluten 3:9 g; RPHI, porridge: 40-g rye flakes inulin:wheat gluten 9:3 g; RPIG, porridge: 40-g rye flakes inulin:wheat gluten 6:6 g; WB, 55-g refined wheat bread. A: $\multimap$, RPHI; - -

displayed, on average, $46 \%(P<0.05)$ and $102 \%(P<0.0001)$ higher concentrations of hydrogen in breath compared with RP55 and RP40, respectively. Hydrogen concentrations were also 43\% $(P<0.05), 48 \%(P<0.0001)$ and $105 \%(P<0.05)$ higher after consumption of RPIG compared with RPHG, RP55 and RP40, respectively (Fig. 5).

The concentration of methane excreted in breath was higher during the whole day ( -30 to $480 \mathrm{~min}$ ) after consumption of RPHI, RP55 and RP40 compared with RPHG $(P<0.05)$ and WB $(P<0 \cdot 01)$. For $\mathrm{AUC}_{0-480 \mathrm{~min}}$, intake of $\mathrm{RP} 55$ resulted in $57 \%$
$(P<0.05)$ higher breath methane concentrations compared with WB (online Supplementary Fig. S1). Overall, the levels of hydrogen and methane excreted in breath did not differ between men and women.

\section{Glucose}

Postprandial plasma glucose concentration after breakfast ( -15 to $125 \mathrm{~min}$ ) was higher after consumption of RP55 compared with RPHI and RP40 and before lunch ( -15 to $230 \mathrm{~min}$ ) 
(A)

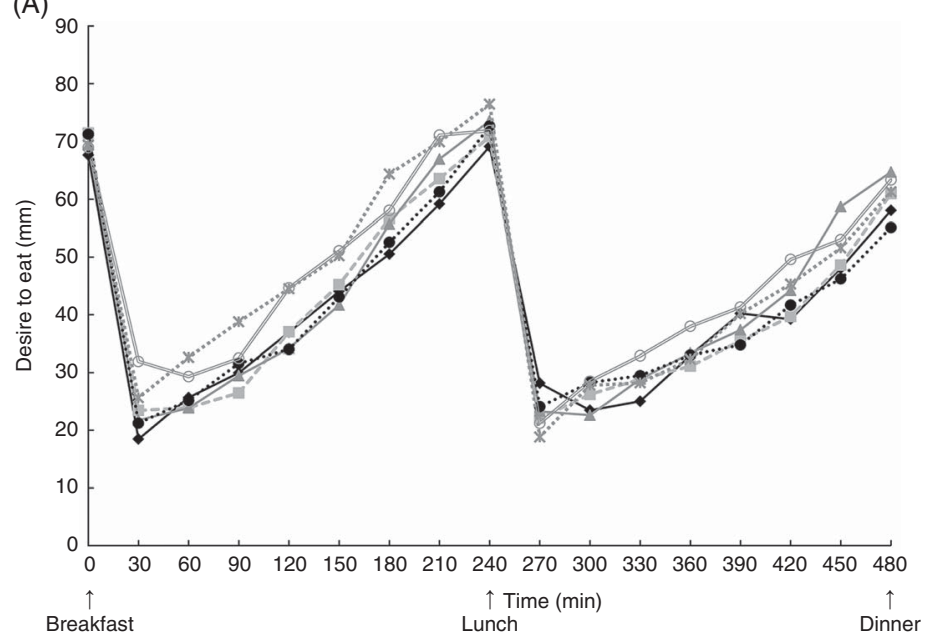

(B)

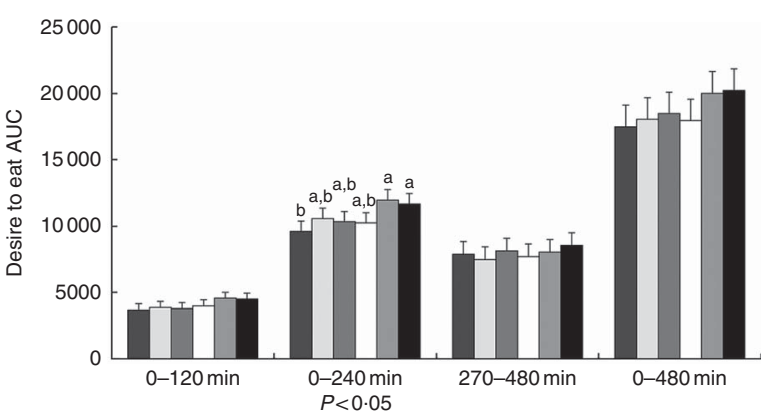

Fig. 4. (A) Mean subjective ratings of desire to eat ( $n 21)$ during the whole day $(0-480 \mathrm{~min})$ after intake of isoenergetic breakfast meals. Subjects reported less desire to eat before lunch from intake of RPHI compared with RP40 $(P<0.05)$. (B) AUC for subjective desire to eat $(n 21)$ after breakfast $(0-120$ min), before lunch (0-240 $\mathrm{min})$, after lunch (270-480 $\mathrm{min})$ and during the whole day (0-480 min) after intake of six isoenergetic breakfast meals. ${ }^{\text {ab }}$ Mean values with unlike letters were significantly different $(P<0.05)$. Analysed by ANCOVA. RP40, porridge: 40-g rye flakes; RP55, porridge: 55-g rye flakes; RPHG, porridge: 40-g rye flakes inulin:wheat gluten $3: 9 \mathrm{~g}$; RPHI, porridge: 40-g rye flakes inulin:wheat gluten 9:3 g; RPIG, porridge: 40-g rye flakes inulin:wheat gluten 6:6 g; WB, 55-g refined wheat bread.

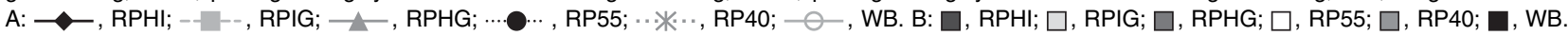

(A)

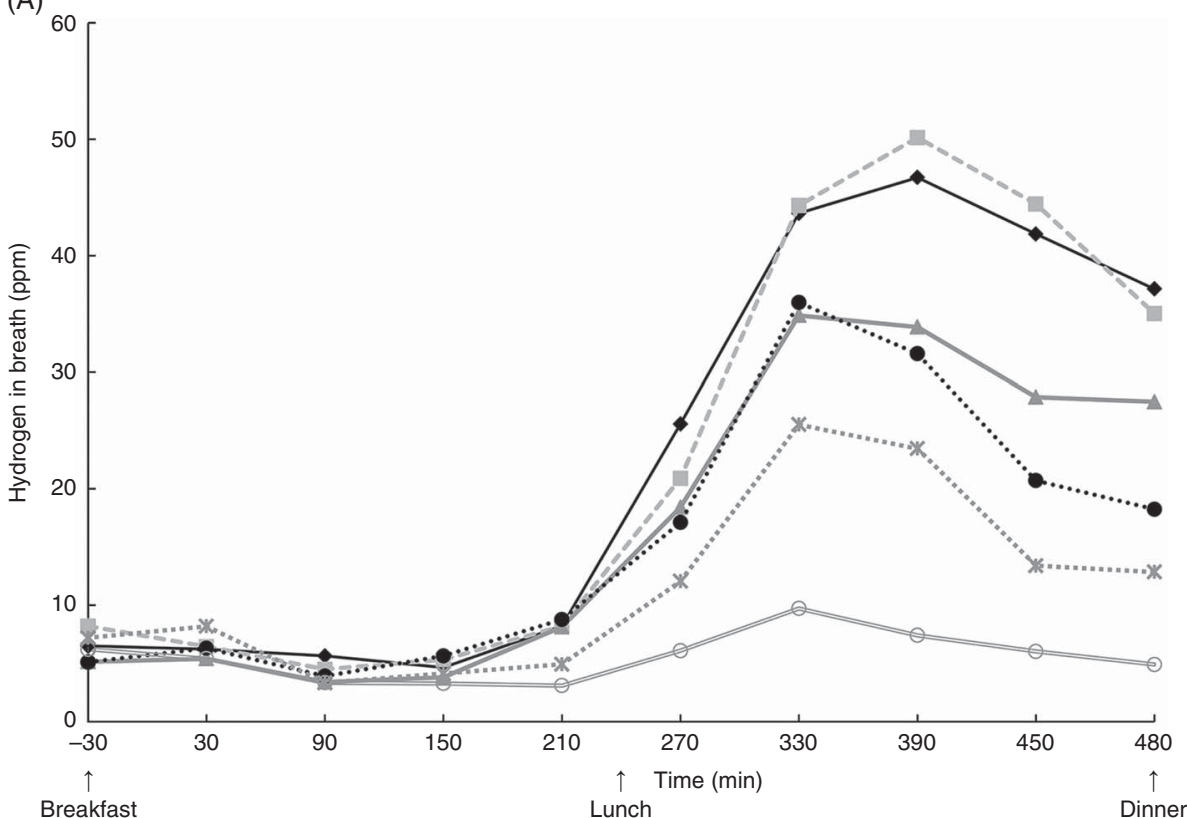

(B)

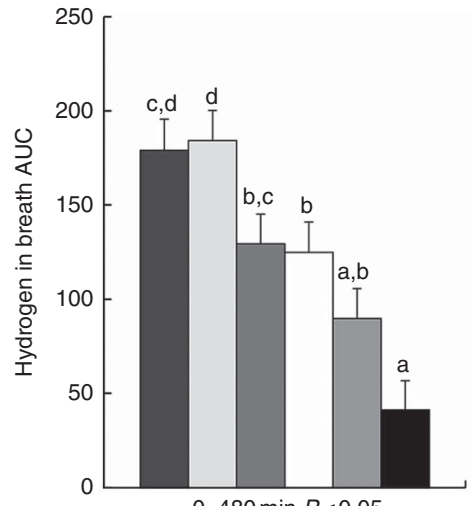

Dinner

Fig. 5. (A) Mean concentrations of hydrogen in breath $(n 17)$ during the whole day ( -30 to 480 min) after intake of six isoenergetic breakfast meals. The concentration was higher during the whole day for RPHI, RPIG, RPHG and RP55 compared with WB $(P<0.01)$, and for RPHI and RPIG compared with RP40 $(P<0.001$ for both

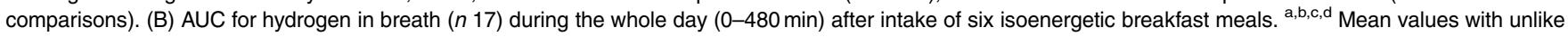
letters were significantly different $(P<0.05)$. Analysed by ANCOVA. RP40, porridge: 40-g rye flakes; RP55, porridge: 55-g rye flakes; RPHG, porridge: 40-g rye flakes inulin:wheat gluten 3:9 g; RPHI, porridge: 40-g rye flakes inulin:wheat gluten 9:3 g; RPIG, porridge: 40-g rye flakes inulin:wheat gluten 6:6 g; WB, 55-g refined

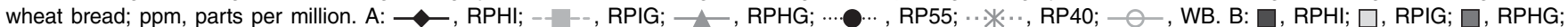
$\square$, RP55; $\square$, RP40; $\square$, WB.

compared with WB $(P<0.05)$ (Fig. 6). Similarly, for AUC $_{-15}$ to $125 \mathrm{~min}$, intake of RP55 resulted in, on average, $7 \%$ $(P<0.05)$ higher plasma glucose levels compared with the other rye porridge meals (except RPIG). After lunch
(275-470 min), on the other hand, the postprandial blood glucose response was lower after consumption of RPHI and RP55 compared with WB $(P<0 \cdot 01$ and $P<0 \cdot 05$, respectively). The plasma glucose $\mathrm{AUC}_{275-470 \mathrm{~min}}$ was, on average, $6 \%$ 
(A)

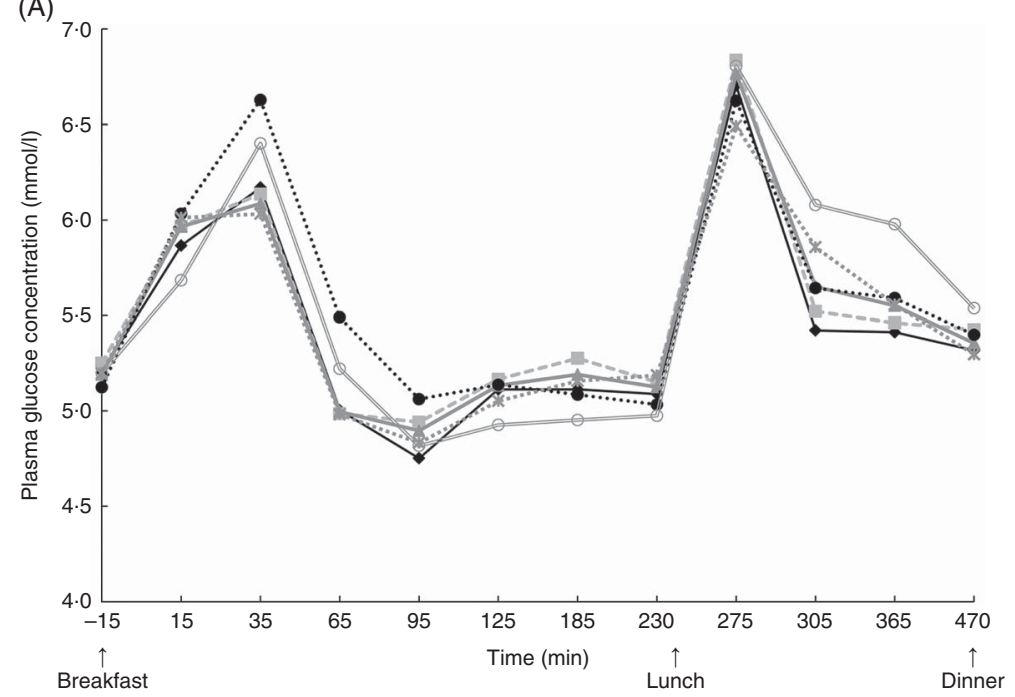

(B)

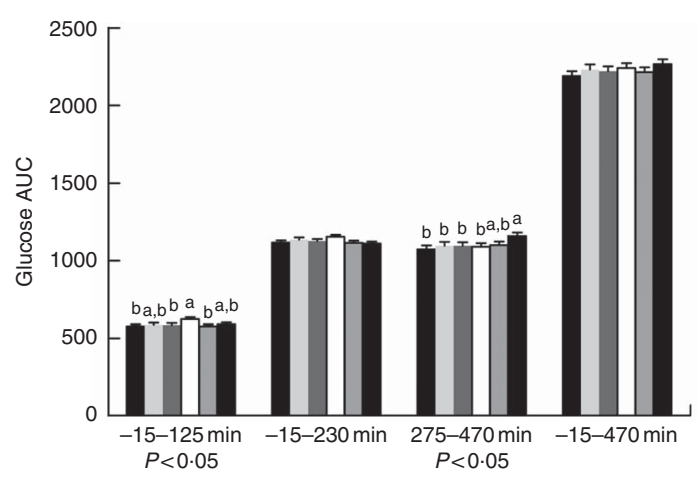

Fig. 6. (A) Mean concentrations of plasma glucose $(n 21)$ during the whole day (0-470 min) after intake of six isoenergetic breakfast meals. The concentration was higher from intake of RP55 compared with RPHI and RP40 after breakfast ( -15 to $125 \mathrm{~min}$ ) and before lunch $(-15$ to $230 \mathrm{~min}) \mathrm{compared}$ with WB (P<0.05). (B) AUC for plasma glucose concentration ( $n 21)$ after breakfast $(-15$ to $125 \mathrm{~min})$, before lunch ( -15 to $230 \mathrm{~min})$, after lunch (275-470 min) and during the whole day ( -15 to $470 \mathrm{~min})$ after intake of six isoenergetic breakfast meals. ${ }^{a, b}$ Mean values with unlike letters were significantly different $(P<0.05)$. Analysed by ANCOVA. RP40, porridge: 40-g rye flakes; RP55, porridge: 55-g rye flakes; RPHG, porridge: 40-g rye flakes inulin:wheat gluten 3:9 g; RPHI, porridge: 40-g rye flakes inulin:wheat gluten 9:3 g; RPIG, porridge: 40-g rye flakes inulin:wheat gluten $6: 6 \mathrm{~g}$; WB, 55-g refined wheat bread. A: - - , RPHI; -- -- RPIG; $\longrightarrow-$, RPHG; ......, RP55; -**. " RP40; ——, WB. B: $\square$, RPHI; $\square$, RPIG; $\square$, RPHG; $\square$, RP55; $\square$, RP40; $\square$, WB.

$(P<0.05)$ lower after intake of the 55 -g rye porridge meals compared with WB (Fig. 6). Overall, there was no difference in postprandial blood glucose response between men and women.

\section{Insulin and glucagon-like peptide-1}

There were no differences in insulin or total GLP-1 concentrations between breakfast meals, or between men and women, irrespective of time interval and statistical model (online Supplementary Fig. S2-S3).

\section{Correlations}

No correlation was found between breath hydrogen ( -30 to $480 \mathrm{~min}$ ) and appetite after lunch (270-480 min). Breath hydrogen ( -30 to $480 \mathrm{~min}$ ) was positively correlated with total dietary fibre content $\left(R^{2} 0.71 ; P<0.0001\right)$ but inversely correlated with plasma glucose after lunch $(275-470 \mathrm{~min})\left(R^{2}-0 \cdot 18\right.$; $P<0 \cdot 0001)$.

\section{Discussion}

High-fibre rye foods have consistently shown appetitesuppressing effects and reduced postprandial insulin and sometimes reduced glucose responses compared with refined wheat $^{(3-13,15)}$. In the present study, we investigated whether the appetite-suppressing effects of whole-grain rye porridge could be enhanced by replacing part of the rye with the rapidly fermented dietary fibre inulin and the plant protein wheat gluten. We also explored the role of gut fermentation on appetite, postprandial glucose, insulin and total GLP-1 concentrations during $8 \mathrm{~h}$ after intake of the breakfast meals.

In agreement with previous studies ${ }^{(3-13)}$, we found that whole-grain rye porridge lowered hunger, increased fullness and lowered desire to eat compared with WB. However, no enhancement of satiety was observed after replacing part of the rye with inulin and wheat gluten. Protein-rich meals are thought to be effective in increasing satiety under isoenergetic conditions ${ }^{(1)}$. However, RPHG did not suppress appetite more than the other breakfast meals. In a study by Lang et $a l .{ }^{(47)}$, no differences in appetite were found between proteins from various sources (wheat gluten included), although the food products tested were isoenergetic and matched for macronutrient content. In a mixed meal, the co-ingestion of carbohydrates and fats may decrease the effect of protein on appetite $^{(47)}$. In addition, we observed differences in branchedchain amino acids (BCAA) between the diets. These differences attributed to the addition of wheat protein (online Supplementary Table S2). Mechanisms explaining protein-dependent satiety may be related to BCAA in circulation, through effects on satiety hormone excretion, such as GLP-1. However, RPHG contained 3-fold more gluten than RPHI, causing a 2-fold difference in BCAA, but without additional effects on satiety. Thus, observed differences in appetite response are possibly more related to the dietary fibre component of the whole-grain rye porridges.

An effect of portion size on appetite was found when comparing the whole-grain rye porridge meals with each other. The larger 55-g rye porridges with or without inulin and wheat gluten increased satiety more than the small $40-\mathrm{g}$ rye porridge, and the effect was strongest during the period before lunch (0-240 min). The importance of portion size was demonstrated 
by Isaksson ${ }^{(48)}$ : inclusion of $55-66-9$ rye per portion porridge lowered appetite, whereas $45-\mathrm{g}$ rye per portion bread did not, in comparison with WB. In contrast, Forsberg et al. ${ }^{(5)}$ showed less pronounced effects on appetite following intake of $80 \mathrm{~g}$ instead of 64-g rye crisp bread compared with WB. The larger breakfast portion may have attenuated the satiety response and affected the subsequent ad libitum food intake at lunch ${ }^{(5)}$. With no difference in appetite response between the small rye porridge and the $\mathrm{WB}$, it appears that more than $40 \mathrm{~g}$ of rye per portion of porridge is needed to significantly increase satiety.

In general, the effects on appetite in our study were weaker after consumption of a standardised lunch meal. Similarly, Isaksson et $a l .{ }^{(7)}$ did not observe any difference in appetite between 55-g whole-grain rye porridge and WB, served as part of complete breakfasts, after intake of a standardised lunch meal, although rye porridge increased satiety before lunch and elicited an increase in breath hydrogen of similar magnitude as we observed from RP55. Because of its size, the standardised lunch meal probably attenuated any differences in appetite after lunch $(275-470 \mathrm{~min})$, which may explain why there was no difference in subsequent ad libitum dinner intake.

Previous studies suggest that the satiating effect of dietary fibre may partly be due to increased gut fermentation and the production of SCFA ${ }^{(20)}$. We observed an early, large and dosedependent increase in breath hydrogen in response to the amount of dietary fibre in the breakfast meals. In contrast, breath methane did not increase in a dose-dependent manner, which could be due to low presence of a methanogenic microflora ${ }^{(41)}$. Hartvigsen et al. ${ }^{(4)}$ observed increased breath hydrogen and SCFA concentrations, and less hunger after lunch, after intake of a semolina porridge with added rye kernels and concentrated arabinoxylans compared with a semolina porridge. Concentrated and soluble arabinoxylans are rapidly fermented in the gut, similarly to inulin ${ }^{(4,20)}$, and inulin has previously shown promising satiating effects ${ }^{(20)}$. Surprisingly, we observed no enhancement of satiety on replacing part of the rye with inulin and wheat gluten in the whole-grain rye porridge, even though extensive gut fermentation occurred 4-8 $\mathrm{h}$ after intake of the breakfast meals.

Fermentable dietary fibre is also important in the control of postprandial glucose response, as SCFA may enter the circulation and reduce hepatic glucose production and circulating NEFA levels, thereby increasing glucose storage and insulin sensitivity ${ }^{(21,49)}$. The early and extensive gut fermentation that occurred after consumption of the 55-g rye porridges could explain why glucose responses after lunch (275-470 min) were lower compared with WB - that is, demonstrating a second meal effect from whole-grain rye porridge. This is supported by our observation and that of others ${ }^{(4,21)}$ of a negative correlation between breath hydrogen and plasma glucose after intake of whole-grain rye. In contrast to our results, Hartvigsen et al. ${ }^{(4)}$ did not find a second meal effect on plasma glucose after consumption of semolina porridge with added rye kernels with or without concentrated arabinoxylans. A reason for the diverging results could be that the magnitude of breath hydrogen from consumption of the 55-g porridge meals with added inulin and wheat gluten in the present study was almost twice as that reported by Hartvigsen et al. ${ }^{(4)}$. The effect of gut fermentation on second meal glucose response from intake of whole-grain rye and different amounts of rapidly fermented dietary fibre warrants further investigation.

Even though there was a clear meal response in glucose concentration, we did not detect any differences in postprandial insulin response between the breakfast meals. Lower insulin levels have commonly been observed in previous studies on rye bread ${ }^{(6,10,11,16,17,50)}$, rye flour porridge ${ }^{(11)}$, rye kernel porridge $^{(4)}$ and boiled rye kernels ${ }^{(10)}$. The lack of difference in insulin response was accompanied by a lack of difference in the total GLP-1 concentrations between breakfast meals. Despite the whole-grain rye porridges having a disintegrated structure $^{(51)}$ and giving rise to extensive gut fermentation, no differences were observed in GLP-1. Previous studies on the effects of whole-grain rye foods on GLP-1 have reported mixed results $^{(4,6,16,17)}$. GLP-1 is released in response to the amount of macronutrients ingested, mainly glucose and lipids ${ }^{(2,52,53)}$. Thus, the lack of difference in GLP-1 levels could be due to the added fat ${ }^{(54)}$ or nutrients provided through the co-ingestion of jam and milk. Our results indicate the importance of evaluating postprandial effects on appetite and metabolism in a mixed meal context before evaluating possible implications for health.

Our study has several strengths, but also some limitations that need to be addressed. We cannot attribute any independent effects to single nutrients, as we evaluated mixed meals. Moreover, the amount of available carbohydrates varied in the breakfast meals, which could explain why RP55 showed significantly higher plasma glucose concentration after breakfast ( -15 to $125 \mathrm{~min}$ ) compared with the other breakfast meals. As we did not analyse SCFA, we cannot be certain that the extensive breath hydrogen excretion also resulted in higher SCFA production, although a link has previously been shown after intake of whole-grain rye ${ }^{(4,55)}$. As the standardised lunch meal most likely obscured the effects by gut fermentation on appetite, the hypothesis that increased gut fermentation is associated with decreased appetite needs to be further addressed in extended postprandial studies. Finally, we only analysed total GLP-1 in a subset of subjects ( $n$ 14). As gut fermentation is believed to stimulate GLP-1 production, we chose to compare breakfast meals containing high (RPHI), medium (RP55) and low (WB) amounts of fermentable dietary fibre.

In conclusion, no further increase in satiety was observed when replacing part of the rye with inulin and wheat gluten, thereby increasing the content of dietary fibre and protein. Evidently, intake of whole-grain rye porridge leads to a dosedependent increase in gut fermentation, and an attenuated plasma glucose concentration after a second meal, but without a corresponding reduction in insulin and GLP-1 response. Further studies are needed to establish causality between appetite, gut fermentation and hormonal responses.

\section{Acknowledgements}

The authors thank the subjects for participating in this study; Gunnel Fransson for chemical analysis of the food products; and Dr Pleunie Hogenkamp for valuable discussions on study set-up.

The study was supported by the BarleyFunFood research programme at the Faculty of Natural Resources and Agricultural 
Sciences, Swedish University of Agricultural Sciences and Lantmännen Research Foundation. The whole-grain rye porridges were provided by Lantmännen. Lantmännen had no role in the design, analysis or writing of this article.

The authors' contributions were as follows: I. L., U. R. and R. L. designed the study; I. L. enrolled subjects, assigned subjects to interventions, conducted the study and wrote the paper; L. S. and R. L. analysed the data; L. S. revised and re-submitted the manuscript. D.-L. W. and P. M. H. provided essential materials; R. L. generated the random allocation sequence and had primary responsibility for the final content. All authors read and approved the final manuscript.

None of the authors has any personal or financial conflicts of interest.

\section{Supplementary material}

For supplementary material/s referred to in this article, please visit https://doi.org/10.1017/S0007114516004153

\section{References}

1. Chambers L, McCrickerd K \& Yeomans MR (2015) Optimising foods for satiety. Trends Food Sci Technol 41, 149-160.

2. Hellström PM (2013) Satiety signals and obesity. Curr Opin Gastroenterol 29, 222-227.

3. Johansson DP, Lee I, Risérus U, et al. (2015) Effects of unfermented and fermented whole grain rye crisp breads served as part of a standardized breakfast, on appetite and postprandial glucose and insulin responses: a randomized cross-over trial. PLOS ONE 10, e0122241.

4. Hartvigsen ML, Lærke HN, Overgaard A, et al. (2014) Postprandial effects of test meals including concentrated arabinoxylan and whole grain rye in subjects with the metabolic syndrome: a randomised study. Eur J Clin Nutr 68, 567-574.

5. Forsberg T, Åman P \& Landberg R (2014) Effects of whole grain rye crisp bread for breakfast on appetite and energy intake in a subsequent meal: two randomised controlled trails with different amounts of test foods and breakfast energy content. Nutr J, 1-9.

6. Hartvigsen ML, Gregersen S, Lærke HN, et al. (2014) Effects of concentrated arabinoxylan and $\beta$-glucan compared with refined wheat and whole grain rye on glucose and appetite in subjects with the metabolic syndrome: a randomized study. Eur J Clin Nutr 68, 84-90.

7. Isaksson H, Tillander I, Andersson R, et al. (2012) Whole grain rye breakfast - sustained satiety during three weeks of regular consumption. Physiol Behav 105, 877-884.

8. Rosén LaH, Östman EM \& Björck IME (2011) Postprandial glycemia, insulinemia, and satiety responses in healthy subjects after whole grain rye bread made from different rye varieties. 2. J Agric Food Chem 59, 12149-12154.

9. Isaksson H, Rakha A, Andersson R, et al. (2011) Rye kernel breakfast increases satiety in the afternoon - an effect of food structure. Nutr J 10, 31.

10. Rosén LA, Östman EM \& Björck IM (2011) Effects of cereal breakfasts on postprandial glucose, appetite regulation and voluntary energy intake at a subsequent standardized lunch; focusing on rye products. Nutr J 10, 7 .

11. Rosén LaH, Silva LOB, Andersson UK, et al. (2009) Endosperm and whole grain rye breads are characterized by low post-prandial insulin response and a beneficial blood glucose profile. Nutr J 8, 42.
12. Isaksson H, Fredriksson H, Andersson R, et al. (2009) Effect of rye bread breakfasts on subjective hunger and satiety: a randomized controlled trial. Nutr $J \mathbf{8}, 39$.

13. Isaksson $\mathrm{H}$, Sundberg B, Aman $\mathrm{P}$, et al. (2008) Whole grain rye porridge breakfast improves satiety compared to refined wheat bread breakfast. Food Nutr Res 52, 1-7.

14. Rosén LAH, Östman EM, Shewry PR, et al. (2011) Postprandial glycemia, insulinemia, and satiety responses in healthy subjects after whole grain rye bread made from different rye varieties. 1. J Agric Food Chem 59, 12139-12148.

15. Breen C, Ryan M, Gibney MJ, et al. (2013) Glycemic, insulinemic, and appetite responses of patients with type 2 diabetes to commonly consumed breads. Diabetes Educ 39, 376-386.

16. Juntunen KS, Laaksonen DE, Autio K, et al. (2003) Structural differences between rye and wheat breads but not total fiber content may explain the lower postprandial insulin response to rye bread. Am J Clin Nutr 78, 957-964.

17. Juntunen KS, Niskanen LK, Liukkonen KH, et al. (2002) Postprandial glucose, insulin, and incretin responses to grain products in healthy subjects. Am J Clin Nutr 75, 254-262.

18. Näslund E, Gutniak M, Skogar S, et al. (1998) Glucagon-like peptide 1 increases the period of postprandial satiety and slows gastric emptying in obese men. Am J Clin Nutr $6 \mathbf{8}$, 525-530.

19. Fernandes J, Vogt J \& Wolever TMS (2011) Inulin increases short-term markers for colonic fermentation similarly in healthy and hyperinsulinaemic humans. Eur J Clin Nutr 65, 1279-1286.

20. Cani PD, Lecourt E, Dewulf EM, et al. (2009) Gut microbiota fermentation of prebiotics increases satietogenic and incretin gut peptide production with consequences for appetite sensation and glucose response after a meal. Am J Clin Nutr 90, 1236-1243.

21. Nilsson AC, Östman EM, Granfeldt Y, et al. (2008) Effect of cereal test breakfasts differing in glycemic index and content of indigestible carbohydrates on daylong glucose tolerance in healthy subjects. Am J Clin Nutr 87, 645-654.

22. Gilbert J, Bendsen NT, Tremblay A, et al. (2011) Effect of proteins from different sources on body composition. Nutr Metab Cardiovasc Dis 21, B16-B31.

23. Acheson $\mathrm{KJ}$, Blondel-Lubrano A, Oguey-Araymon S, et al. (2011) Protein choices targeting thermogenesis and metabolism. Am J Clin Nutr 93, 525-534.

24. Cappelleri JC, Bushmakin AG, Gerber RA, et al. (2009) Psychometric analysis of the Three-Factor Eating Questionnaire-R21: results from a large diverse sample of obese and non-obese participants. Int J Obes 33, 611-620.

25. Johansson G \& Westerterp KR (2008) Assessment of the physical activity level with two questions: validation with doubly labeled water. Int J Obes (Lond) 32, 1031-1033.

26. Dye L \& Blundell JE (1997) Menstrual cycle and appetite control: implications for weight regulation. Hum Reprod $\mathbf{1 2}$, 1142-1151.

27. Maffeis C, Bonadonna RC, Consolaro A, et al. (2006) Ghrelin, insulin sensitivity and postprandial glucose disposal in overweight and obese children. Eur J Endocrinol 154, 61-68.

28. Ulmius M, Johansson A \& Önning G (2009) The influence of dietary fibre source and gender on the postprandial glucose and lipid response in healthy subjects. Eur J Nutr 48, 395-402.

29. Bondia-Pons I, Nordlund E, Mattila I, et al. (2011) Postprandial differences in the plasma metabolome of healthy Finnish subjects after intake of a sourdough fermented endosperm rye bread versus white wheat bread. Nutr J 10, 116.

30. Blundell J, de Graaf C, Hulshof T, et al. (2010) Appetite control: methodological aspects of the evaluation of foods. Obes Rev 11, 251-270. 
31. Schneeman BO (1999) Fiber, inulin and oligofructose: similarities and differences. J Nutr 129, 1424S-1427S.

32. European Commission (1998) Commission directive 98/64/EC of 3 September 1998 establishing community methods of analysis for the determination of amino-acids, crude oils and fats, and olaquindox in feedingstuffs and amending directive 71/939. Official Journal of the European Communities L527, $14-28$.

33. European Commission (1993) Commission directive 93/28/ EEC of 4 June 1993 amending annex I to the third directive 72/ 199/EEC establishing community methods of analysis for the official control of feedingstuffs. Official Journal of the European Communities L179, 8-10.

34. Theander O, Aman P, Westerlund E, et al. (1995) Total dietary fiber determined as neutral sugar residues, uronic acid residues, and Klason lignin (the Uppsala method): collaborative study. J AOAC Int 78, 1030-1044.

35. McCleary BV \& Monaghan DA (2002) Measurement of resistant starch. J AOAC Int 85, 665-675.

36. McCleary BV, Murphy A \& Mugford DC (2000) Measurement of total fructan in foods by enzymatic/spectrophotometric method: collaborative study. J AOAC Int 83, 356-364.

37. McCleary BV \& Codd R (1991) Measurement of $(1 \rightarrow 3)$, $(1 \rightarrow 4)-\beta$-D-glucan in barley and oats: a streamlined enzymic procedure. J Sci Food Agric 55, 303-312.

38. Loosveld AA, Grobet PJ \& Delcour JA (1997) Contents and structural features of water-extractable arabinogalactan in wheat flour fractions. J Agric Food Chem 45, 1998-2002.

39. Johansson DP, Lee I, Risérus U, et al. (2015) Effects of unfermented and fermented whole grain rye crisp breads served as part of a standardized breakfast, on appetite and postprandial glucose and insulin responses: a randomized cross-over trial. PLOS ONE 10, e0122241.

40. Whybrow S, Stephen JR \& Stubbs RJ (2006) The evaluation of an electronic visual analogue scale system for appetite and mood. Eur J Clin Nutr 60, 558-560.

41. Rumessen J (1992) Hydrogen and methane breath tests for evaluation of resistant carbohydrates. Eur J Clin Nutr $\mathbf{4 6}$, 77-90.

42. Kim K-R, Rhee S-D, Kim HY, et al. (2005) KR-62436, 6-\{2-[2(5-cyano-4,5-dihydropyrazol-1-yl)-2-oxoethylamino]ethylamino\} nicotinonitrile, is a novel dipeptidyl peptidase-IV (DPP-IV) inhibitor with anti-hyperglycemic activity. Eur J Pharmacol 518 63-70.
43. Bak MJ, Wewer Albrechtsen NJ, Pedersen J, et al. (2014) Specificity and sensitivity of commercially available assays for glucagon-like peptide-1 (GLP-1): implications for GLP-1 measurements in clinical studies. Diabetes Obes Metab 16, $1155-1164$

44. Bland JM \& Altman DG (1995) Statistics notes: calculating correlation coefficients with repeated observations: part 1 - correlation within subjects. BMJ 310, 446.

45. Brouns F, Bjorck I, Frayn KN, et al. (2005) Glycaemic index methodology. Nutr Res Rev 18, 145.

46. Flint A, Raben A, Blundell JE, et al. (2000) Reproducibility, power and validity of visual analogue scales in assessment of appetite sensations in single test meal studies. Int J Obes Relat Metab Disord 24, 38-48.

47. Lang V, Bellisle F, Oppert J, et al. (1998) Satiating effect of proteins in healthy subjects: a comparison of egg albumin, casein, gelatin, soy protein, pea protein, and wheat gluten. Am J Clin Nutr 67, 1197-1204.

48. Isaksson H (2011) Satiating effects of rye foods. PhD Thesis, Swedish University of Agricultural Sciences.

49. Russell WR, Baka A, Björck I, et al. (2016) Impact of diet composition on blood glucose regulation. Crit Rev Food Sci Nutr 56, 541-590.

50. Leinonen K, Liukkonen K, Poutanen K, et al. (1999) Rye bread decreases postprandial insulin response but does not alter glucose response in healthy Finnish subjects. Eur J Clin Nutr 53, 262-267.

51. Vázquez-Gutiérrez JL, Johansson D \& Langton M (2016) Effects of added inulin and wheat gluten on structure of rye porridge. LWT - Food Sci Technol 66, 211-216.

52. Brubaker PL \& Anini Y (2003) Direct and indirect mechanisms regulating secretion of glucagon-like peptide-1 and glucagon-like peptide-2. Can J Physiol Pharmacol 81, $1005-1012$

53. Holst JJ (2007) The physiology of glucagon-like peptide 1. Physiol Rev 87, 1409-1439.

54. Gibbons C, Caudwell P, Finlayson G, et al. (2013) Comparison of postprandial profiles of ghrelin, active GLP-1, and total PYY to meals varying in fat and carbohydrate and their association with hunger and the phases of satiety. J Clin Endocrinol Metab 98, E847-E855.

55. Ibrügger S, Vigsnæs LK, Blennow A, et al. (2014) Second meal effect on appetite and fermentation of wholegrain rye foods. Appetite 80, 248-256. 